\title{
The importance of research on the perception of successful aging
}

\begin{abstract}
The study of successful aging has grown significantly in recent years. We highlight the interest of researchers in the perception of old age among the elderly. Self-perception can reflect others' perceptions of self, and can be incorporated internally throughout life. The present paper proposes a brief reflection on the main findings regarding the research on the perception of successful aging and its the impact on variables such as physical health, emotional health and longevity. Results indicated that study of the subjective perception of old age can be a relevant line of research in favor of a better conceptualization of the successful aging construct.
\end{abstract}

Keywords: perception of aging, successful aging, aging
Volume 2 Issue 5 - 2017

\author{
Elizabeth do Nascimento, Fernanda Heringer \\ Moreira Rosa, Pricila Cristina Correa Ribeiro \\ Department of Psychology, Universidade Federal de Minas \\ Gerais, Brazil
}
Correspondence: Elizabeth do Nascimento, Departamento de Psicologia, Universidade Federal de Minas Gerais, Brazil,Tel 55-31-991953393, 55-31-34096275,
E-mail bethdonascimento@gmail.com

Received: October 0I, 2017 | Published: December 06, 2017

\section{Introduction}

Historically, there are three basic patterns to understand old age: pathological aging, involving the predominance of medical pathologies; the normal aging, indicating the functioning without biological and mental pathologies and without disabilities; and the successful aging, invoking a higher than expected aging pattern in a given context. ${ }^{1,2}$

Despite researchers' efforts to develop models for successful aging, there is still no academic consensus on the definition of the term. ${ }^{3,4}$ There are three main explanatory models on successful old age: the Rowe and Kahn model ${ }^{5}$ The Socio-Emotional Selectivity ${ }^{1}$ and the Corrective and Preventive Proactivity. ${ }^{6}$ We also highlight researches focused on the subjective perception of the elderly in relation to their aging. This is the focus of the present reflection. The aim is briefly outline the conceptual focus regarding prevalent research questions, main themes and variables that correlate with the subjective perception of old age.

Many studies on perception of old age emerged from critiques regarding previous researches. For instance, Rowe and Kahn criticized the tendency of researchers to consider only objective markers of physical health and to disregard the subjective perception of the elderly. One of the assumptions of these previous researches is that positive and / or negative attitudes about self are internalized and can be part of self. Scholars have identified that self-perception may reflect others' perceptions of self, so aging stereotypes would be created and incorporated internally throughout life and would contribute to the formation of self-perception about aging. ${ }^{7,8}$

The development and operationalization of self-stereotypes about aging have identifiable characteristics:

I. aging stereotypes arise in childhood and are reinforced during adult life,

II. aging stereotypes can influence the stereotype of aging of the self in a non-conscious level

III. in old age, the stereotypes of aging act on the interpretation of this stage of life. ${ }^{9}$

Therefore, experiences and self-perceptions of aging are both determined by biological and psychological processes, individual life history, attitudes, expectations, ideals of society, and culture. The purpose of this study was to carry out a review about the perception of successful old age with qualitative designs. The study sought to answer the following questions: is successful aging studied having similar theoretical perspectives between countries? Is there consensus on what has been observed about successful aging?

\section{Method}

It is a descriptive research, developed through a review of the concept of successful old-age perception. The following electronic databases were used as the research source: LILACS; INDEXPSI; PSyCOINFO; MEDLINE. The selected papers were restricted to scientific articles and other forms of publication were excluded. The searches were conducted between November 2015 and November 2016. The descriptors for the search were: successful old age; perception of successful old age; successful aging; successful aging perception and self-perceptions of aging.

\section{Data analysis}

The first analysis was made through the reading of the abstracts and, at this stage, the articles that responded to the objective of the present research were selected. The inclusion criteria were:

i. Research that presented qualitative questions about the aging phenomenon from the perspective of the elderly.

ii. The perception of successful old age represented in categories.

iii. Articles in Portuguese and/or English.

The period of time delimited in the search contemplated publications of the last 20 years (1996 to 2016). We excluded studies that did not present any a priori theoretical basis. The publications were analyzed considering the following criteria: the definition of the outcome of interest, the formulations of the qualitative questions and the theoretical basis used.

\section{Results}

All the abstracts that included the descriptors, separated or combined, were located, making a total of 2,724 articles. At the 
first level of analysis, 1,907 (70\%) articles were discarded because they did not present qualitative questions about the construct. Of the remaining $30 \%, 777$ articles in a second stage were eliminated because their theoretical bases were not represented and there were no categorizations for the responses about successful aging perception. In this last step, 40 articles were selected for the final analysis. It is important to emphasize that six articles (15.4\%) inserted in the review (whose contents met the inclusion criteria) were derived from reading the articles selected a priori.

The main themes derived from the responses of the elderly are essentially related to well-being orientation ${ }^{10}$ In the presence of resources - especially those of a financial nature ${ }^{11}$ In the engagement to life - as a concern with health care or active lifestyle ${ }^{12}$ In having positive social relations ${ }^{13}$ In having health and physical and mental independence ${ }^{14}$ and in subjective and psychological well-being. ${ }^{15}$ It is noteworthy that the denial of successful old age, even if in a few cases is usually represented in the answers of the elderly. ${ }^{16}$

The domain subjective and psychological well-being is the most prevalent to define successful aging. It demonstrates the important impact of subjectivity as signaling for a satisfactory aging process. Contrary to this data, we can note the negative perception of successful aging being mentioned, even if less frequently. At this point, it is inferred the possibility that some elderly people have a greater difficulty accepting aging, either by a process resulting from their own state of life, or by the stereotyped structures on old age in society. Some authors point out that the conceptions of aging itself permeate two stages of expectations. ${ }^{17}$ First, the expectations internalized before old age and the second stage of expectations are linked to the situations that the elderly individuals are living in the present time. Underlying these situations, negative expectations could have an adverse impact on the elderly in the course of life.

It was also possible to observe that the articles listed tend to choose theoretical references based on the theoretical models of Rowe and $\mathrm{Kahn}^{5}$ and Life Span ${ }^{1}$, these models of great impact and extension in the gerontological literature. Reflecting on this prevalence, it is noticeable that the amount of studies analyzed dates back to the beginning of the twenty-first century, when there was a greater dissemination and consolidation in methodological and empirical terms of these two models.

Researches about aging are often based on open interview questions. For example: Do you believe that you are experiencing a successful old age? Why? The usual questions have an unspecific way of inquiring the elderly about what is aging well, not allowing selfreflection (eg, what is old age for you?). It is possible that, even in the more general questions, many answers tend to / could lead individuals to report their own experiences about aging. However, it is assumed that the increase in researches investigating indicators of selfperception of aging, in a specific way, would enrich the theoretical definitions in this field as well as allow a better understanding of the true state of life of the elderly.

Finally, the perception of successful old age is understood as multidimensional characteristic. Its domains are physical, cognitive, emotional-motivational and social ${ }^{5}$. These domains are present in people of different nationalities. However, the degree of relevance given to each of them can be differentiated according to cultural values. It is believed that the advancement of research on the subjective perception of old age can broaden the understanding of the association with other variables, such as: proactive engagement of the elderly with regard to their own development, affective states, longevity, and others.

\section{Acknowledgements}

This research received no specific grant from any funding agency in the public, commercial, or not-for-profit sectors.

\section{Conflict of interest}

The authors have no conflict of interest.

\section{References}

1. Baltes PB, Baltes MM. Psychological perspectives on successful aging: The modelo of selective optimization with compensation. Successful aging: perspectives from the behavioral sciences. Cambridge University Press, USA; 1990

2. Baltes PB, Smith J. New frontiers in the future of aging: from successful aging of the young old to the dilemmas of the forth age. Gerontology. 2003;49(2):23-135.

3. Katz S, Calasanti T. Critical perspectives on successful aging: does it "appeal more than it illuminates? The Gerontologist. 2015;55(1):26-33.

4. Peterson NM, Martim P. Tracing the origins of success: implications for successful aging. The Gerontol. 2015;55(1):5-13.

5. Rowe JW, Kahn RL. Successful aging, Gerontologist. 1998;37(4):433-440.

6. Kahana E, Kahana B, Lee JE. Proactive approaches to successful aging: one clear path through the forest. Gerontology. 2014;60(5):466-474

7. Kotter GD, Hess TM. The impact of age stereotypes on self-perceptions of aging across the adult lifespan. The Journals of Gerontology, Series B: Psych Sciences and Social Sciences. 2012;67(5):563-571.

8. Keong AMPA. Auto percepção do envelhecimento em idosas viúvas (Dissertation). Psychologu University, Lisboa University, Portugal; 2010.

9. Levy BR. Mind matters: cognitive and physical effects of aging selfestereotypes. Journal of Gerontol: Psych Sciences. 2003;58(4):203-211.

10. Collings P. "If you got everything, it's good enough": perspectives on successful aging in a canadian inuit community". Journal of CrossCultural Geront. 2001;16:127-155.

11. Tan J, Ward L, Ziaian T. Experiences of chinese immigrants and anglo-australians ageing in Australia: A Cross-cultural perspective on successful ageing. J Health Psychol. 2015;15(5):697-706.

12. Jopp DS, Wozniak D, Damarin AK, et al. How could lay perspectives on successful aging complement scientific theory? Findings from a US and a German Life-Span sample. The Gerontol. 2015;55(1):91-106.

13. Nguyen AL, Seal DW. Cross-cultural comparison of successful aging definitions between chinese and Hmong elders in the United States. $J$ Cross Cult Gerontol. 2014;29(2):153-171.

14. Hilton MJ, Gonzales CA, Saleh M, et al. Perceptions of successful aging among older latinos, in cross cultural context. $J$ Cross Cult Gerontol. 2012;27(3):183-199.

15. Jopp DS, Wozniak D, Damarin AK, et al. How could lay perspectives on successful aging complement scientific theory? Findings from a U.S. and a German Life-Span sample. The Gerontol. 2015;55(1):91-106. 
16. Craciun C. Successful aging-utopia or the result of lifelong learning? Meaning and representations of ageing in romanian elderly. Ageing Int. 2012;37(4):373-385.
17. Levy BR, Slade MD, Kunkel, SR, et al. Longevity increased by positive self-perceptions of aging. Journal of Personality and soc Psych. 2002;83(2):281-270. 